\title{
Application of Electronic Nose Based on Fast GC for Authenticity Assessment of Polish Homemade Liqueurs Called Nalewka
}

\author{
Magdalena Śliwińska $^{1}$ - Paulina Wiśniewska ${ }^{1}$ - Tomasz Dymerski ${ }^{1}$. \\ Waldemar Wardencki ${ }^{1}$ • Jacek Namieśnik ${ }^{1}$
}

Received: 16 November 2015 / Accepted: 15 February 2016/Published online: 29 February 2016

(C) The Author(s) 2016. This article is published with open access at Springerlink.com

\begin{abstract}
The possibility of application of electronic nose based on fast GC for differentiation of three types of cherry liqueurs, namely Polish homemade liqueurs called nalewka, commercially available liqueurs labeled as nalewka, and commercial liqueurs, was investigated. This device was equipped with two parallel connected columns with different stationary phases coupled to two ultrasensitive flame ionization detectors ( $\mu$-FIDs). Four data analysis methods were used, namely principal component analysis (PCA), discriminant function analysis (DFA), soft independent modeling of class analogies (SIMCA), and statistical quality control (SQC). Application of electronic nose based on fast GC system allows identification of volatile organic compounds and compare aroma profiles of all three types of cherry liqueurs. Only DFA allows for full discrimination of all groups of samples. Application of PCA, SIMCA, and SQC analysis allows only for the differentiation of homemade and commercial liqueurs, but not for separation between two groups of commercial liqueurs. The electronic nose based on fast GC provides a possibility of effective and rapid aroma profile comparison (the total time of analysis is $93 \mathrm{~s}$ ) of selected alcohols. In addition, the identification and tentative semiqualitative comparison of the amount of selected compounds of the volatile fraction of these beverages using the HS-SPME/GC $\times$ GC-TOFMS technique
\end{abstract}

Magdalena Śliwińska

m.e.sliwinska@gmail.com

Tomasz Dymerski

tomasz.dymerski@gmail.com

1 Department of Analytical Chemistry, The Chemical Faculty, Gdansk University of Technology, 11/12 Narutowicza, St., 80-233 Gdańsk, Poland were done. This work presents the proposal of protection of this traditional product through elaborated methodology and rapid authentication assessment of Polish nalewka made from cherries.

Keywords Electronic nose based on fast GC - Cherry liqueurs $\cdot$ Nalewka $\cdot$ Authenticity test $\cdot$ Chemometrics

\section{Introduction}

Poland is one of the biggest cherry producers. Information from the FAOSTAT shows that in Poland, ca. 41,063 t of this fruit was produced in 2012 (FAOSTAT 2012). Due to such amount of cherries produced, it is necessary to process the fruit into foodstuff, namely juices, jams, and liqueurs. According to legal regulations, liqueur is a colorless or colored sweetened spirit drink produced by flavoring ethyl alcohol or distillate of agricultural origin. The required minimum content of ethanol in liqueurs is $15 \%$ vol. (Regulation [EC] No. 110/2008). The production of liqueurs is based very often on the use of products of agricultural origin (herbs, fruits, and fruit juices) or the foodstuff such as dairy products and wines. In addition, natural or synthetic flavorings or essential oils can also be used to the production. Liqueurs are mostly colored by the addition of caramel and honey (Hallgarten 1983; Śliwińska et al. 2015).

Production of homemade liqueurs is Polish centuries-long tradition. The original name of this alcohol is nalewka. Till now, in Poland, the nalewka name is still in use. The first mention of this drink can be found in 18 th century literature. Homemade liqueurs were mainly prepared in the manor houses of Polish noblemen as well as in the households of townsfolk and peasants. In general, the traditional Polish nalewka is made exclusively from fruits, grain alcohol, and sugar. A broadly defined nalewka is a homemade alcoholic drink prepared by pouring spirit over the fresh 
fruits in the proportion which allows for obtaining the alcoholic strength of the final product of ca. 30-60\% (Fiedoruk 2006). Traditional homemade liqueurs called nalewka do not contain artificial flavors and colors.

Till now, cherry liqueurs were analyzed in relation to the content of phenolic compounds using a high performance liquid chromatography coupled to different types of detectors, such as electron capture detector (ECD), diode-array detector (DAD), mass spectrometry (MS), and MS/MS (Rødtjer et al. 2006; Ieri et al. 2012). The contents of phenolic compounds in liqueurs produced from different varieties of Prunus cerasus cv. Stevns cherry (Rødtjer et al. 2006) and P. mahaleb L. variety were compared with those measured in commercially available Mirinello di Torremaggiore liqueur (Ieri et al. 2012). Additionally, two samples of commercial Polish cherry liqueurs were studied for antioxidant properties using electron paramagnetic resonance (EPR), nuclear magnetic resonance (NMR), and ultraviolet-visible (UV-VIS) spectroscopy (Polak and Bartoszek 2015). Also, the contents of flavonoids in German liqueurs made from cherries and prunes were analyzed by using HPLC-CRD (de Pascual-Teresa et al. 1998).

Articles describing the investigations of another spirit drink made from cherries, so-called cherry spirit, can be found in the published literature (Śliwińska et al. 2015) This spirit type is produced exclusively via alcoholic fermentation of stone fruits, fruits without stones, and must, which is followed by distillation (Regulation [EC] No. 110/2008; Wiśniewska et al. 2015a). Cherry spirits are mainly analyzed in relation to ethyl carbamate content (Lachenmeier et al. 2005; Lachenmeier et al. 2006; Andrey 1987). Ethyl carbamate is carcinogenic; it forms during the fermentation of foodstuff(Zimmerli and Schlatter 1991). The highest concentrations of this compound were determined in spirits made from stone fruits (Dennis et al. 1989). The content of ethyl carbamate in cherry spirits was measured by means of gas chromatography (Śliwińska et al. 2015; Lachenmeier et al. 2005; Dennis et al. 1989; Lachenmeier 2005) and Fourier transform infrared spectroscopy (Lachenmeier 2005). In literature, there are information about comparison of the volatile fractions of cherry spirits produced from different varieties of Oblačinska, Celery's, Rexle, Heiman's Ruby, and Heiman's Conserve cherries by using GC-FID and GC-MS. In addition, all samples were subjected to sensory evaluation, while the content of benzaldehyde was analyzed by means ofHPLC (Nikićević et al. 2011)

Nowadays, more and more often, instead of the traditional gas chromatography, the fast gas chromatography (fast GC) in food analysis is used. The main advantage of the application of fast GC is the possibility to obtain a short time of analysis. Until now, this technique was used several times to provide the analysis of major volatile compounds in distilled alcoholic beverages (Namara et al. 2005), differentiation of the types of beer, wine, vodka, whisky, and tequila (Ragazzo-Sanchez et al. 2008) and for classification of Chilean wines of different vintages and geographic origin (Beltrán et al. 2008). Most of fast GC systems are traditionally equipped with one chromatographic column. However, the devices with different designs are also manufactured. One of the examples is the Heracles II electronic nose based on fast GC equipped with two independent chromatographic columns with stationary phases of different polarity and two flame ionization detectors. This type of electronic nose was used for the study presented in this paper. In literature can be found an information about application of this equipment for comparison of aroma profiles of whiskey originating from different distilleries (Kundu et al. 2006), differentiation of grape wine varied of age and brand (Yang et al. 2012), comparison and discrimination of aroma profiles of Chinese liqueurs (Peng et al. 2015; Xiao et al. 2014), and discrimination spirits according botanical origin (Wiśniewska et al. 2015b). There is minor information about the application of electronic nose based on fast GC for the analysis of homemade nalewka and commercial liqueurs made from cherries.

The aim of this work was to report for the first time the application of electronic nose based on fast GC for the authenticity assessment of three types of cherry liqueurs: homemade nalewka, commercially available alcohols labeled as nalewka, and commercial liqueurs. Determination of the similarities and possibility of differentiation of the aroma profiles of the aforementioned spirit drinks by applying four statistical methods of data analysis, i.e., PCA, DFA, SIMCA, and SQC were another objectives in this work. In addition, the additional investigation was done connected with identification and tentative semiqualitative comparison of the amount of selected compounds of the volatile fraction of these beverages by the use of headspace solid-phase microextraction combined with two dimensional gas chromatography (HS-SPME/GC $\times$ GC-TOFMS).

\section{Materials and Methods}

\section{Materials}

\section{Samples}

The studies were performed on 14 liqueurs made from cherries. There were three different groups of liqueurs: homemade liqueurs called nalewka $(n=5)$, commercial liqueurs labeled as nalewka $(n=5)$, and commercial liqueurs $(n=4)$. Homemade liqueurs in 2014 were produced in Pomeranian voivodeship in Poland. Cherries (P. cerasus) used for the production of liqueurs called nalewka were harvested in August 2014 in the same region. These homemade liqueurs were produced exclusively with cherries, spirit, sugar, and water. Homemade liqueurs called nalewka have been prepared according to one of the most popular recipes, but the amount of ingredients used was different. After harvest, cherries were 
thoroughly washed, placed in to the jars, and covered with sugar. Jars were sealed tightly for a range of 1-4 days. After that, spirits and water were added. Again, jars were closed and left in a warm place. Maceration process took 30 days. After this time, homemade liqueurs were filtered through gauzes and the remaining liquids were poured into tightly sealed glass bottles. All commercial beverages were produced in large distilleries of Poland and these beverages were purchased in local markets in 2014. During the research for each sample, three repetitions were performed. All samples were stored in glass bottles for 1 month prior to analysis.

\section{Chemicals}

Deionized water of high purity from MilliQ A10 Gradient/ Elix System (Millipore, Bedford, MA, USA) was used throughout the research. The mixture of n-alkanes of carbon chain lengths from C6 to C16 from Sigma-Aldrich, (St. Louis, MO, USA) was utilized. The following chemical compounds, namely ethanol, acetic ester, 1-butanol, propanoic acid ethyl ester, 3-methyl-1-butanol, butanoic acid ethyl ester, 1-octen-3one, and octanal, were also included as a standards purchased from Sigma-Aldrich (Poznań, Poland).

\section{Sample Preperation}

Samples were prepared in the proportion of $1.75 \mathrm{ml}$ of liqueur and $6.25 \mathrm{ml}$ of deionized water and were then transferred into 20 -ml vials. All samples were sealed with caps closing with $20 \mathrm{~mm}$ thick PTFE/silicone membrane.

\section{Headspace Generation}

\section{Headspace Generation According to Electronic Nose Based on Fast GC}

For the headspace generation, in the case of using electronic nose based on fast GC system, the following analytical procedure was applied. The vial with the liquid sample was introduced into the autosampler (Odor Scanner HS 100, Gerstel, Mülheim, Germany). Gas gained from the headspace of the sample was used for the analysis. The incubation time was $20 \mathrm{~min}$ in $40^{\circ} \mathrm{C}$ and agitation speed was maintained on the level of $500 \mathrm{rpm}$. After the incubation process, the gas sample was taken from the headspace of the sample and transferred from vial to the GC injector port at $200{ }^{\circ} \mathrm{C}$ (Plutowska and Wardencki 2008).

\section{Headspace Generation According to $G C \times G C$-TOFMS}

The headspace generation for $\mathrm{GC} \times \mathrm{GC}$-TOFMS procedure was preceded by HS-SPME extraction. A Gerstel autosampler (MPS autosampler, Gerstel, Mülheim, Germany) with agitator and SPME fiber conditioning station was used to extract the volatiles from the nalewkas and liqueurs. Before the extraction, the samples were kept at $40{ }^{\circ} \mathrm{C}$ for 5 min and agitated with a magnetic stirrer at $700 \mathrm{rpm}$. Extraction was carried out at $40{ }^{\circ} \mathrm{C}$ for $20 \mathrm{~min}$ using a DVB/CAR/PDMS SPME fiber of $50 / 30-\mu \mathrm{m}$ thickness and 2-cm length (Sigma-Aldrich, Munich, Germany). After the extraction, the fiber was removed from the vial and transferred to the injector of a gas chromatograph for thermal desorption of the analytes at $250{ }^{\circ} \mathrm{C}$ for $5 \mathrm{~min}$ (Plutowska and Wardencki 2008).

\section{Instrumentation}

The electronic nose based on fast GC called Heracles II (Alpha M.O.S., Toulouse, France) equipped with two parallel connected columns with different stationary phases coupled to two ultra sensitive flame ionization detectors ( $\mu$-FIDs) was used for the analysis. The first non-polar column was MTX$5(10 \mathrm{~m} \times 0.18 \mathrm{~mm} \times 0.4 \mu \mathrm{m}$ film thickness $)$ and the second column with medium polar stationary phase MXT-1701 $(10 \mathrm{~m} \times 0.18 \mathrm{~mm} \times 0.4 \mu \mathrm{m}$ film thickness $)$ was applied. The separation of analytes was performed using the following temperature chromatographic program: initial temperature $40{ }^{\circ} \mathrm{C}$ (kept for $18 \mathrm{~s}$ ) then ramped at $3{ }^{\circ} \mathrm{C} / \mathrm{s}$ to $270{ }^{\circ} \mathrm{C}$ (kept for $30 \mathrm{~s}$ ). The hydrogen N5.0 class (Linde Gaz, Poland) was used as a carrier gas. Detector temperature was $270{ }^{\circ} \mathrm{C}$ in. The alkane C6-C16 standard solution was used for the calculation of Kovat's indices and the identification of VOCs. The identification was confirmed using AroChemBase library.

The GC $\times$ GC system (Agilent 7890 A) equipped with liquid nitrogen-based quad-jet cryogenic modulator and a split/splitless injector, coupled with Pegasus 4D time-of-flight mass spectrometer(LECOCorp., St. Joseph, MI, USA), were used for the analysis. The first non-polar column was Equity-1 $(30 \mathrm{~m} \times 0.25 \mathrm{~mm}$ i.d. $\times 0.25 \mu \mathrm{m}$ film thickness) purchased from Supelco (Bellefonte, PA, USA). The second column with polar stationary phase SolGel-Wax $(2 \mathrm{~m} \times 0.1 \mathrm{~mm}$ i.d. $\times 0.1 \mu \mathrm{m}$ film thickness $)$ was purchased from SGE Analytical Science (Austin, TX, USA). The separation was performed using the following temperature program for the primary oven: initial temperature $40^{\circ} \mathrm{C}$, kept for $3.5 \mathrm{~min}$, ramped at $7^{\circ} \mathrm{C} / \mathrm{min}$ to $250^{\circ} \mathrm{C}$, and held for $5 \mathrm{~min}$. The secondary oven temperature was programmed from $45^{\circ} \mathrm{C}$, kept for $3.5 \mathrm{~min}$, ramped at $7{ }^{\circ} \mathrm{C} / \mathrm{min}$ to $255^{\circ} \mathrm{C}$, and held for $2 \mathrm{~min}$. The carrier gas was helium (N6.0 class) at a constant flow rate at $1.0 \mathrm{ml} / \mathrm{min}$. The MS transfer line and the MS source temperature was $250^{\circ} \mathrm{C}$. The modulation time was $6 \mathrm{~s}$. The mass spectra data acquisition rate was $125 \mathrm{spectra} / \mathrm{s}$. The data were collected over a mass range of 40-400 m/z and the voltage was $1600 \mathrm{~V}$.

\section{Data Analysis}

Four chemometric methods, principal component analysis (PCA), discriminant function analysis (DFA), soft 
independent modeling of class analogies (SIMCA), and statistical quality control (SQC) have been used for data analysis of results obtained by the use of electronic nose based on fast GC. All these methods were performed in Alpha Soft (V12.4, Alpha M.O.S, Toulouse, France).

Principal component is a chemometric linear unsupervised and pattern recognition technique used for analyzing and reducing the dimensionality of numerical datasets in a multivariate problem (Ragazzo-Sanchez et al. 2009). PCA is used to reduce the number of descriptive variables or detecting relationships between the variables. This statistical procedure is based on determining a set of components that are linear (Wilson et al. 2000; Ragazzo-Sanchez et al. 2009; GhasemiVarnamkhasti et al. 2012a).

Discriminant function analysis is a multivariate technique for describing a mathematical function and it allows distinguishing among predefined groups of samples. DFA is used when the assumptions of a linear regression are met. The cases are classified into groups using a discriminant prediction equation to examine differences between or among groups. The primary aim of DFA is the prediction of group membership based on linear combination of interval variables. This statistic method determines whether groups differ from each other and identifies the possible subgroups (Śliwińska et al. 2014).

The method of soft independent modeling of class analogy is used to compare unknown samples with the reference group. In the SIMCA model, such comparisons are made with one specific group form database. In this method, a separate model is created for each class, which is based on the principal component analysis. For each group, the number of significant components of the model is selected individually in accordance with the method used. In case only one principal component is significant for the entire class, the mean value of this

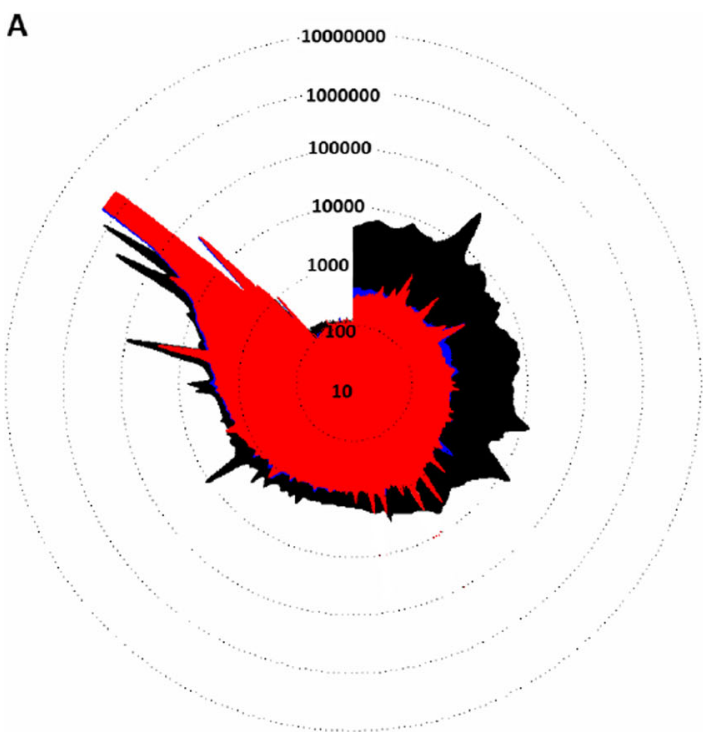

component together with the associated vector becomes the model for a given class. SIMCA classifier is usually used when we deal with two or more classes that consist of tight or less tight clusters of objects (Śliwińska et al. 2014; Ghasemi-Varnamkhasti et al. 2012b). The classifier of statistical quality control is an effective tool for conducting the statistical monitoring of product quality. The obtained data indicate the distances between analyzed samples and the profile of product being compared.

Analysis of the data obtained by the use of the GC $\times \mathrm{GC}$ TOFMS system was done using the algorithm for peak deconvolution implemented in the ChromaTOF software (LECO Corp., version 4.24). Analytes were tentatively identified through the use of NIST 2011 mass spectral library with minimum similarity value of $90 \%$.

\section{Results and Discussion}

\section{Chromatography Analysis}

The radar maps obtained on column MTX-5 and MTX-1701 of electronic nose based on fast GC for different groups of cherry liqueurs are shown in Fig 1. The comparison of radar maps showed significant differences in volatile compounds profile between three groups of liqueurs. Radar maps show that homemade liqueurs called nalewka have higher amount of volatile compounds (Fig. 1) than other types of liqueurs. The smallest number of peaks was collected in group samples of commercial liqueurs labeled as nalewka. This situation can lead to the conclusion that application of electronic nose based on fast GC is useful to rapidly demonstrate that aroma profiles of three groups of liqueurs are different.

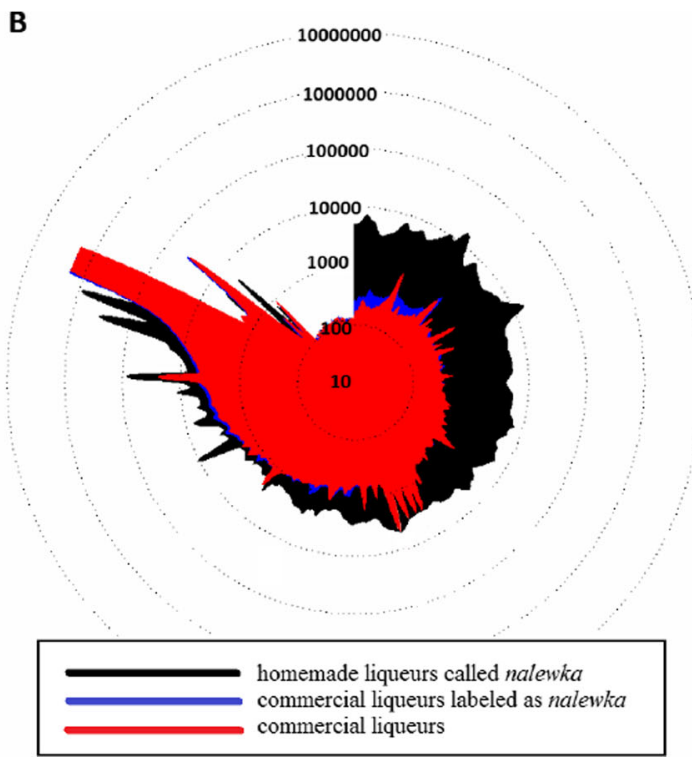

Fig. 1 Radar maps of different kinds of cherry liqueurs collected by electronic nose based on fast GC with two different separation columns: MTX-5 (a) and MTX-1701 (b) 
Table 1 Compounds identified in the volatile fraction of homemade liqueurs called nalewka, commercial liqueurs labeled as nalewka, and commercial liqueurs detected by electronic nose based on fast GC

\begin{tabular}{|c|c|c|c|c|c|c|c|c|}
\hline \multirow[t]{2}{*}{ Compound } & \multicolumn{2}{|c|}{ Retention time } & \multicolumn{2}{|c|}{ Kovats $\mathrm{RI}_{\mathrm{EXP}}$} & \multicolumn{2}{|c|}{ Kovats $\mathrm{RI}_{\mathrm{LIT}}$} & \multirow[t]{2}{*}{ Sensory discription } & \multirow[t]{2}{*}{ References } \\
\hline & C. I & C. II & C. I & C. II & C. I & C. II & & \\
\hline Ethanol & 15.24 & 18.29 & 435.22 & 566.55 & 437 & 564 & Alcoholic, pungent & Allegrone et al. (2006) \\
\hline Acetic ester & 22.09 & 24.66 & 614.19 & 685.03 & 609 & 673 & $\begin{array}{l}\text { Fruity, orange, pineapple, } \\
\text { pungent, sweet }\end{array}$ & $\begin{array}{l}\text { Bosch-Fusté et al. (2007); } \\
\text { Demyttenaere et al. (2003); } \\
\text { Pino et al. (2005); Echeverría et al. (2003); } \\
\text { Jordán et al. (2002); Quijano et al. (2007); } \\
\text { Mattheis et al. (2005) }\end{array}$ \\
\hline 1-butanol & 25.54 & 31.15 & 661.34 & 770.60 & 651 & 768 & Cheese, fermented, fruity & Jordán et al. (2002); Da Porto et al. (2003) \\
\hline $\begin{array}{l}\text { Propanoic } \\
\text { acid ethyl ester }\end{array}$ & 29.55 & 31.08 & 711.38 & 771 & 709 & 766 & Acetone, fruity & Da Porto et al. (2003); Pino et al. (2003) \\
\hline $\begin{array}{l}\text { 3-methyl-1- } \\
\text { butanol }\end{array}$ & 31.26 & 36.06 & 730.60 & 832.23 & 728 & 842 & $\begin{array}{l}\text { Alcoholic, bitter, fermented, } \\
\text { fruity, malty, pungent }\end{array}$ & $\begin{array}{l}\text { Da Porto et al. (2003); Echeverría et al. (2003); } \\
\text { Pino et al. (2003); Maia et al. (2004) }\end{array}$ \\
\hline $\begin{array}{l}\text { Butanoic } \\
\text { acid ethyl ester }\end{array}$ & 37.32 & 38.42 & 798 & 861.25 & 799 & 864 & $\begin{array}{l}\text { Fruity, banana, pineapple, } \\
\text { strawberry, sweet }\end{array}$ & $\begin{array}{l}\text { Demyttenaere et al. (2003); } \\
\text { Pino et al. (2005); Maia et al. (2004); } \\
\text { Joulain et al. (2004); } \\
\text { Mahattanatawee et al. (2005) }\end{array}$ \\
\hline 1-octen-3-one & 52.74 & 54.81 & 977.80 & 1073.41 & 979 & 1066 & Herbaceous, metallic & Buettner (2004); Rouseff et al. (2009) \\
\hline Octanal & 54.36 & 56.72 & 997.14 & 1091.1 & 998 & 1090 & Citrus, floral, fruity, green & $\begin{array}{l}\text { Bosch-Fusté et al. (2007); } \\
\text { Buettner (2004) Culleré et al. (2004); } \\
\text { Gürbüz et al. (2006) }\end{array}$ \\
\hline
\end{tabular}

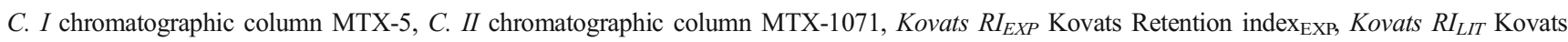
Retention index $\mathrm{LIT}_{\mathrm{L}}$

Volatile compounds detected in the headspace of cherry liqueur samples were investigated using their Kovats retention indices and standard substances. Table 1 lists the identified volatile compounds in all kinds of cherry liqueurs. The main peak is ethanol because the range of ethanol content in all samples was $30 \%$ vol. to $40 \%$ vol. During the production process of liqueurs, the fruits kept are for a limited period in ethanol. Ethyl esters such as acetic ester, propanoic acid ethyl ester, and butanoic acid ethyl ester are compounds which can be characterized by a fruity flavor (Bosch-Fusté et al. 2007; Demyttenaere et al. 2003; Pino et al.
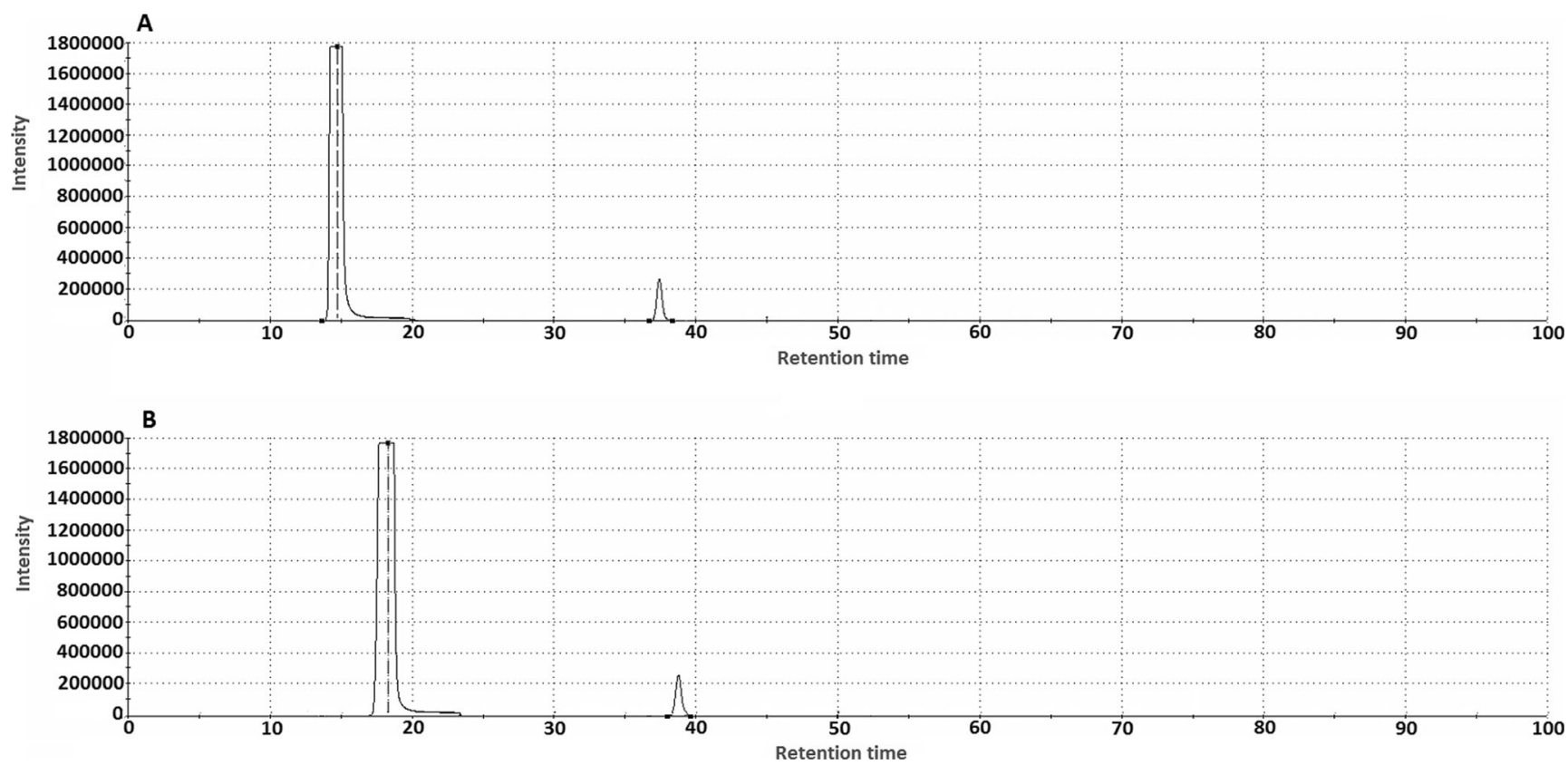

Fig. 2 The chromatogram of butanoic acid ethyl ester solution with ethanol content obtained by the use of electronic nose based on fast GC with two different separation columns: MTX-5 (a) and MTX-1701 (b) 
2005; Echeverría et al. 2003; Jordán et al. 2002; Quijano et al. 2007; Mattheis et al. 2005; Da Porto et al. 2003; Escudero et al. 2007; Pino et al. 2003). Ethyl acetate is ester present in a wide variety of fruits and natural food products. This compound is responsible for the fresh and fruity aroma of ripening fruit. On the other hand, in the case of high concentration, acetic ester has unpleasant aroma which might be associated with the polish nail remover (Tešević et al. 2009). Butanoic acid ethyl ester and acetic ester are commonly present esters in foodstuff. These compounds have no specific aroma of any one type of fruit, but they can be connected with sweet aroma. Similar properties have butanoic acid ethyl ester and propanoic acid ethyl ester and for this reason, they can be used as flavors in cherry, rum, and chewing gum (De Rovira Sr 2008; The Good Scents Company Information System). Acetic ester is another flavor ester. It has unpleasant (Brenntag Food and Nutrition Europe) or pleasant flavor (fruity flavor) which is consistent with other ethyl esters, e.g., propanoic acid ethyl ester, butanoic acid ethyl ester (Bosch-Fusté et al. 2007; Demyttenaere et al. 2003; Pino et al. 2005; Pino et al. 2003). It depends on the amount of this compound in food product. Higher alcohols are formed, interalia, from sugars during the alcoholic fermentation process. Higher alcohols have positive (fruity) and negative (fermented) impacts on aroma of alcohol beverages (Tešević et al. 2009; De Rovira Sr 2008; Quijano et al. 2007; Demyttenaere et al. 2003). 1-Butanol is one of the compounds important for authenticity assessment of raw materials of spirit beverages (Christoph and Bauer-Christoph 2006). The compound 1-octen-3-one has unpleasant flavor (herbaceous, metallic). Most often, it occurs in beverages made from grapes (Buettner 2004), but also in other fruits (Rouseff et al. 2009). Octanal is an aldehyde compound characterized by fruity and pleasant aroma (Bosch-Fusté et al. 2007; Buettner 2004: Culleré et al. 2004; Gürbüz et al. 2006). All these compounds are present in cherries and beverages produced with cherry (Nikićević et al. 2011; Sun et al. 2010).

For verification of the identification of substances presented in Table 1, the standard water solutions of each single compound were prepared only with addition of $30 \%$ etanol

Table 2 The identification of selected compounds from the volatile fraction of homemade liqueurs called nalewka, commercial liqueurs labeled as nalewka, and commercial liqueurs using HS-SPME/GC $\times$ GC-TOFMS.

\begin{tabular}{|c|c|c|c|c|c|c|c|c|}
\hline \multirow[t]{2}{*}{ Compound } & \multirow[t]{2}{*}{$\mathrm{RT}_{\mathrm{I}}$} & \multirow[t]{2}{*}{$\mathrm{RT}_{\text {II }}$} & \multirow[t]{2}{*}{ U.m. ${ }^{\mathrm{a}}$} & \multicolumn{3}{|c|}{ Peak area ${ }^{\mathrm{b}}$} & \multirow{2}{*}{$\begin{array}{l}\text { Sensory } \\
\text { discription }\end{array}$} & \multirow[t]{2}{*}{ References } \\
\hline & & & & $\begin{array}{l}\text { H. } \\
\text { liqueurs } \\
\text { called } \\
\text { nalewka }\end{array}$ & $\begin{array}{l}\text { C. } \\
\text { liqueurs } \\
\text { labeled } \\
\text { as } \\
\text { nalewka }\end{array}$ & $\begin{array}{l}\text { C. } \\
\text { liqueurs }\end{array}$ & & \\
\hline 1-hexanol & 748 & 4.80 & 56 & $* * *$ & $* * *$ & * & $\begin{array}{l}\text { Fruity, floral, } \\
\text { green, } \\
\text { herbaceous, } \\
\quad \text { sweet }\end{array}$ & $\begin{array}{l}\text { Setkova et al. (2007); Seung-Joo et al. (2006); Bianchi et al. } \\
\text { (2007); Fan and Qian (2006); Bonvehí and Coll (2003) }\end{array}$ \\
\hline 1-octanol & 1054 & 4.22 & 56 & $* * *$ & * & * & $\begin{array}{l}\text { Floral, green, } \\
\text { herbaceous }\end{array}$ & $\begin{array}{l}\text { Mahattanatawee et al. (2005); Setkova et al. (2007); Carasek anc } \\
\text { Pawliszyn (2006); Tsakiris et al. (2004) }\end{array}$ \\
\hline $\begin{array}{l}\text { Heptanoic acid } \\
\text { ethyl ester }\end{array}$ & 1084 & 3.04 & 88 & $* * *$ & $* *$ & $* *$ & Fruity & Pino et al. 2005; Mahattanatawee et al. (2005) \\
\hline $\begin{array}{r}\text { Benzoic acid } \\
\text { ethyl ester }\end{array}$ & 1180 & 4.48 & 105 & $* * *$ & * & $*$ & $\begin{array}{l}\text { Fruity, minty, } \\
\text { musty, tea }\end{array}$ & $\begin{array}{l}\text { Perestrelo et al. (2006); Carasek and Pawliszyn (2006); Sampaio } \\
\text { and Nogueira (2006) }\end{array}$ \\
\hline 1-nonanol & 1186 & 4.07 & 56 & * & * & $* * *$ & $\begin{array}{l}\text { Floral, fruity, } \\
\text { green }\end{array}$ & Mahattanatawee et al. (2005); Narain et al. (2007) \\
\hline Linalool & 1198 & 2.79 & 71 & $* * *$ & * & $* *$ & $\begin{array}{l}\text { Floral, fruity, } \\
\text { green, } \\
\text { lemon, } \\
\text { sweet }\end{array}$ & $\begin{array}{l}\text { Da Porto et al. (2003); Gürbüz et al. (2006); Alissandrakis et al. } \\
\text { (2005); Lermusieau et al. (2001); Murakami et al. (2003); Lee } \\
\text { and Noble (2003) }\end{array}$ \\
\hline $\begin{array}{l}\text { Benzeneacetic } \\
\text { acid ethyl } \\
\text { ester }\end{array}$ & 1264 & 4.64 & 91 & $* *$ & $*$ & $* * *$ & $\begin{array}{l}\text { Floral, fruity, } \\
\text { spicy, sweet }\end{array}$ & $\begin{array}{l}\text { Pino et al. 2005; Setkova et al. (2007); Alissandrakis et al. (2007) } \\
\text { Xu et al. (2007) }\end{array}$ \\
\hline $\begin{array}{l}\text { Nonanoic acid } \\
\text { ethyl ester }\end{array}$ & 1336 & 3.02 & 88 & $* * *$ & $*$ & $* *$ & Waxy & Pino et al. (2005) \\
\hline $\begin{array}{l}\text { Decanoic acid } \\
\text { ethyl ester }\end{array}$ & 1450 & 3.03 & 88 & $* *$ & $*$ & $* * *$ & Fruity, grape & $\begin{array}{l}\text { Setkova et al. (2007); Chen et al. (2006); Riu-Aumatell et al. } \\
\text { (2006) }\end{array}$ \\
\hline
\end{tabular}

U.m. (unique mass) - unique ion $(\mathrm{m} / \mathrm{z})$ used for peak area determination, identified as the unique ion by ChromTOF data analysis. $* * *, * *, *$ symbols are the representation of the values of chromatographic peak areas in the range of $90.1-100 \%, 30.1-40 \%$, and $0.1-10 \%$, respectively, regarding the highest value of chromatographic peak area for given compound

$R T_{I}$ first dimension retention time, $R T_{I I}$ second dimension retention time, H. liqueurs called nalewka homemade liqueurs called nalewka, $C$. liqueurs labeled as nalewka commercial liqueurs labeled as nalewka, C. liqueurs commercial liqueurs 
content. The concentration of these substances in the solution was $10 \mathrm{ppm} v / v$.

Comparing two chromatograms obtained by the use of MTX-5 and MTX-1701 columns, it can be noticed that peaks with different retention times are observed in Fig. 2, which presents peaks of butanoic acid ethyl ester and ethanol. This is due to different polarity of stationary phases of these columns (Xiao et al. 2014). The difference in retention times between the two columns was about $1.5 \mathrm{~s}$.

Additionally, the comparative analysis of volatile fraction of homemade liqueurs called nalewka, commercial liqueurs labeled as nalewka, and commercial liqueurs using HSSPME/GC $\times$ GC-TOFMS was made to explain the basis of discrimination of these alcohols.

In Table 2, the identification of selected compounds present in volatile fraction of three concerned alcohols was presented. The identification was confirmed by the comparison of experimental data with mass spectra included in the NIST 2011 mass spectral library. The threshold value of similarity parameter was established at 900 (which means $90 \%$ of conformity of obtained experimental spectrum with the mass spectrum from the database). Additionally, in this table, the tentative semiqualitative comparison of the amount of the abovementioned compounds was shown. All these compounds have been previously described in the literature concerning cherry studies (Sun et al.2010) and can be evaluated with a fruity and floral aroma. Seven out of the ten of selected compounds, namely 1-hexanol, 1-octanol, heptanoic acid ethyl ester, benzoic acid ethyl ester, linalool, and nonanoic acid ethyl ester, appear in the nearly close concentration in each type of sample of three investigated group: homemade liqueurs called nalewka, commercially available alcohols labeled as nalewka, and commercial liqueurs. Probably all of these compounds are originating from fruits, because during the preparation of nalewka, the fruits, sugar, and ethanol addition are used exclusively. The manufacturing process of homemade liqueurs called nalewka is followed by three main steps and is much more complex than production of commercial beverages. The first step of production of homemade nalewka is when fresh fruits are covered with sugar; subsequently, the maceration process which most often takes 3-8 weeks is the middle step and filtration of beverage is the last step.

In the production of commercial beverages, especially in the case companies possessing large distilleries, the fruit concentrates are usually used to reduce production costs (Hernández Gómez Sun et al. 2009). This is one of the main reasons of the occurring differences in composition of homemade liqueurs and commercial beverages. Differences of the amount of compounds can be found, for example, in the case of decanoic acid, 1-nonanol, and benzeneacetic acid ethyl esters.

\section{Statistic Methods}

Using electronic nose based on fast GC, the chromatographic peak area is treated as an input data, for chemometric analysis. All samples are plotted in space and clustered according to the degree of similarity and difference in the data. These parameters are related to the number and size of chromatographic peaks recorded by the electronic nose based on fast GC. To compare aroma profiles of three groups of cherry liqueurs, all chromatographic peaks were used. The chromatographic profile could be represented as an odor map using PCA, DFA, SIMCA, and SQC.

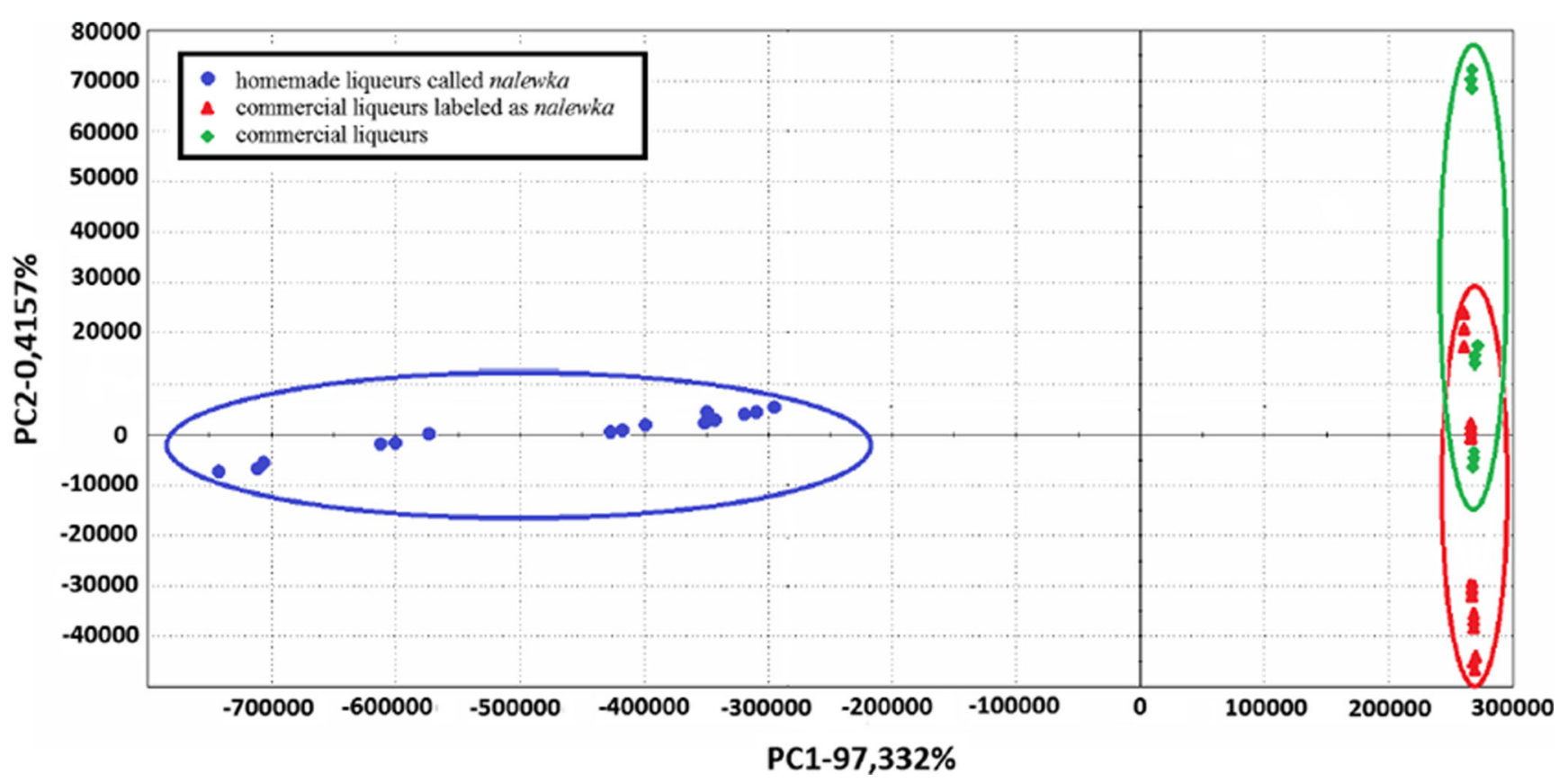

Fig. 3 PCA plots of three groups of cherry liqueurs using electronic nose based on fast GC 


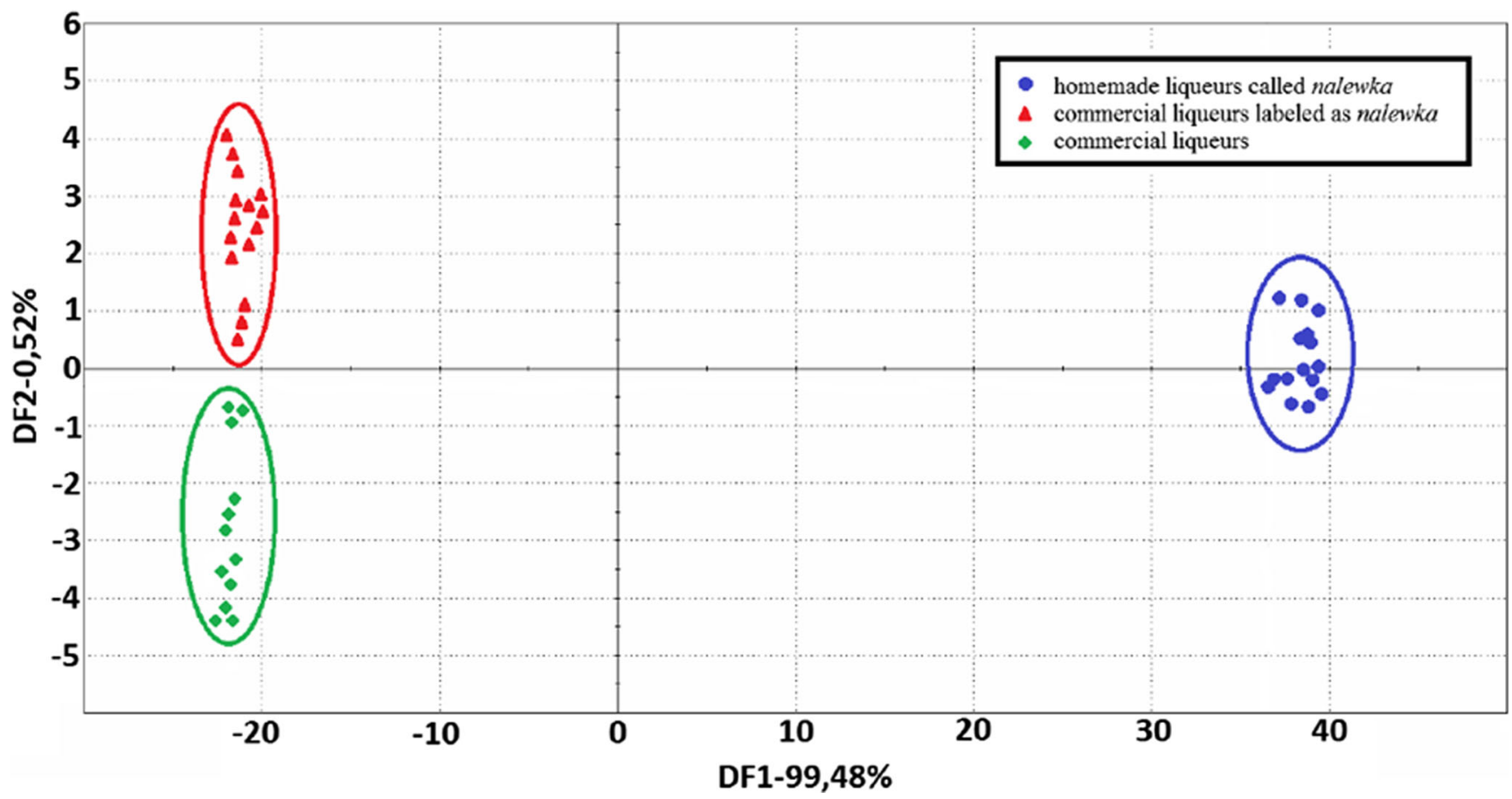

Fig. 4 DFA plots of three groups of cherry liqueurs using electronic nose based on fast GC

Principal component analysis was performed to identify patterns of correlation with individual composition variables involved in the discrimination among three groups of cherry liqueurs. The odor map based on PCA showed clear discrimination of homemade and commercial cherry liqueurs based on their volatile composition. In Fig. 3, the PCA score plot of comparison aroma profiles of different kind of cherry liqueurs is represented. PCA results showed that the first two principal components accounted for $97.75 \%$ of total variance. Liqueur samples appear grouped into two classes: homemade liqueurs called nalewka are situated on the second and third quadrants of the diagram whereas the samples of commercial liqueurs are located on the first and fourth quadrants of graph. Points corresponding to the two groups of commercial liqueurs intersect, so it is not possible to distinguish them from each other.
The DFA diagram corresponding to the same data and sensors which provided the PCA diagram is shown in Fig. 4. The DFA method identifies DF1 and DF2 which explain 99.48 and $0.52 \%$ of the variability in the initial data set, and which are represented as the axes of the DFA plot. Similarly to PCA, the graph is divided into two parts. Homemade liqueurs called nalewka are situated on the first and fourth quadrants of the graph. However, application of DFA analysis allows distinguishing between all three groups of liqueurs. There is a clear separation between commercial liqueurs labeled as nalewka and commercial liqueurs (Fig. 3).

SIMCA classification and PCA can be used to visualize the distance between the classes (Olsson et al. 2000). The area corresponding to the given class is shown on each plot as the blue rectangle in the left corner. As shown on the plots,
Fig. 5 SIMCA classification plot of three groups of cherry liqueurs using electronic nose based on fast GC

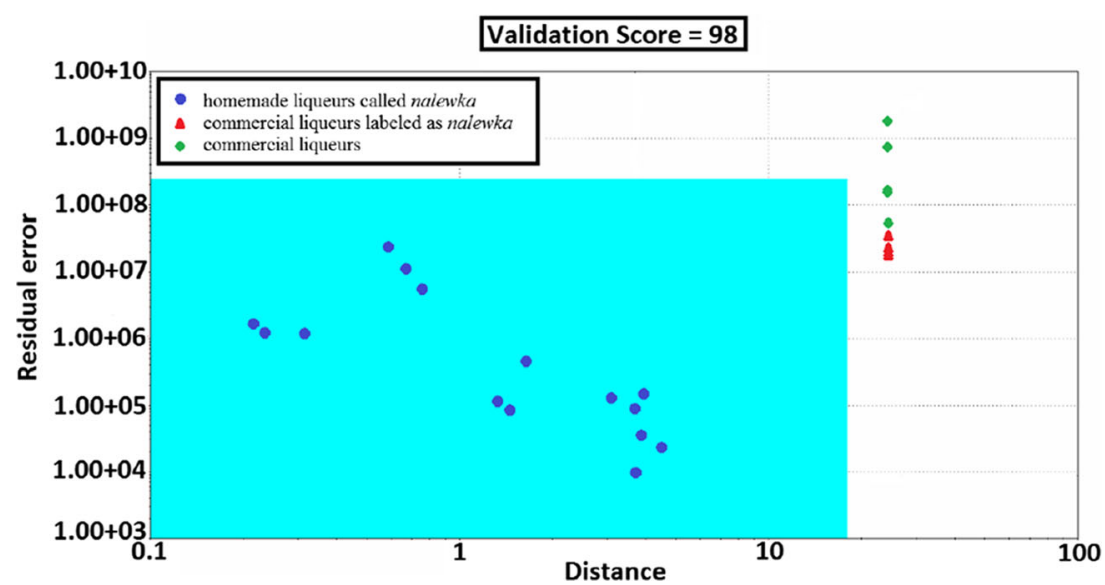


Fig. 6 SQC classification plot of three groups of cherry liqueurs using electronic nose based on fast GC

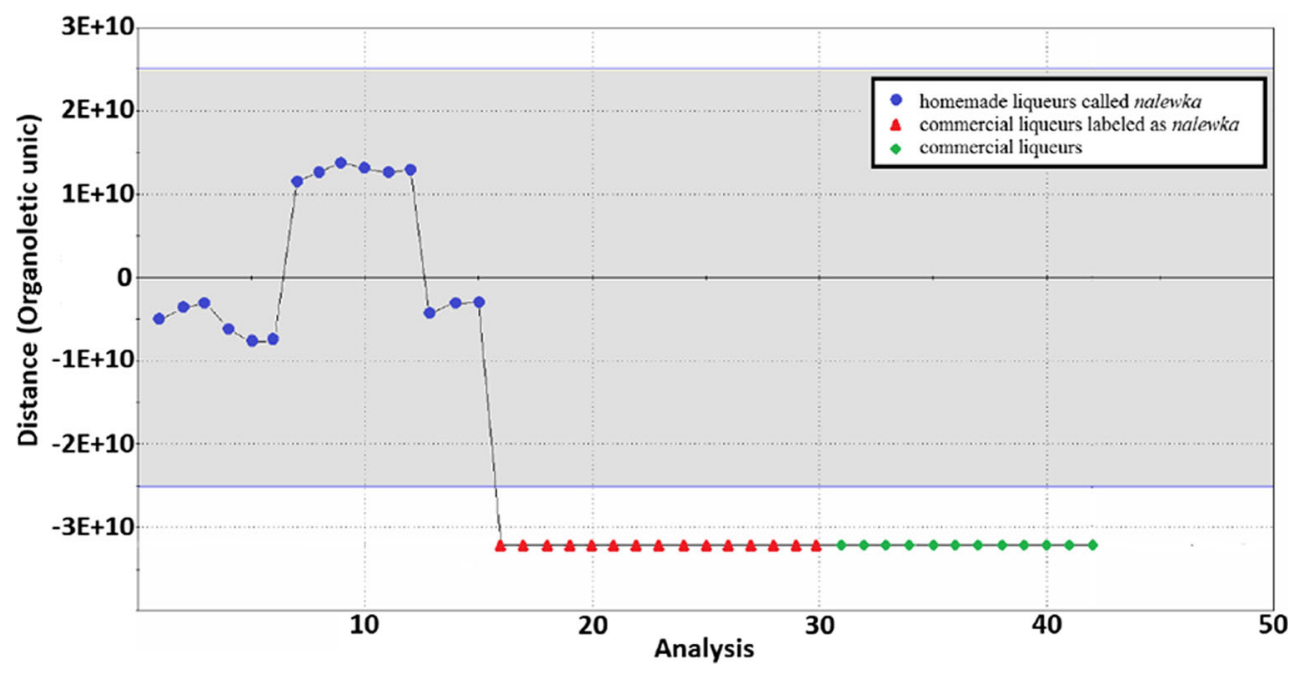

all liqueur samples were assigned correctly to the corresponding class. In Fig. 5, validation score is 98 and obtained a significant distinction between of homemade and commercial groups of cherry liqueurs. Very small distance between the two groups of commercial liqueur samples can be observed. Points relating to both groups of commercial liqueur samples are located in a narrow cluster. On the other hand, the points relating to homemade liqueur samples are arranged in a large space, which may be indicative of diverse aroma profile of these drinks. The result of SIMCA classification is similar to the results obtained by using PCA.

The statistical quality control (SQC) representation allows for rapidly evaluating quality control with a simple visual assessment of the sample quality. Figure 6 shows the result of the SQC depending on homemade liqueurs as reference group. As in the case of PCA and SIMCA, points relating to homemade liqueur samples are located in a large area. On the other hand, samples belonging to both groups of commercial liqueurs are on the same line and are difficult to distinguish. It can be assumed that commercial liqueurs have minimal differences in the aroma profiles.

The verification on chemometric methods regarding suitability were obtained by the use of comparison of aroma profiles of all the data that obtained chromatogram interpretation (Fig. 7). Pattern discrimination index is an indicator which takes into account differences between groups obtained from investigated volatile fractions of samples. Index closer to $100 \%$ means that there is a greater distance between centers of gravity and smaller dispersion within groups. In this case, pattern discrimination index is only $22.94 \%$ in comparison between commercial liqueurs labeled as nalewka and commercial liqueurs. For this reason, it can be concluded that the two groups of commercial beverages from large distilleries have very small differences of aroma profiles. The results
Fig. 7 Results of comparison pattern discrimination index of three groups of cherry liqueurs

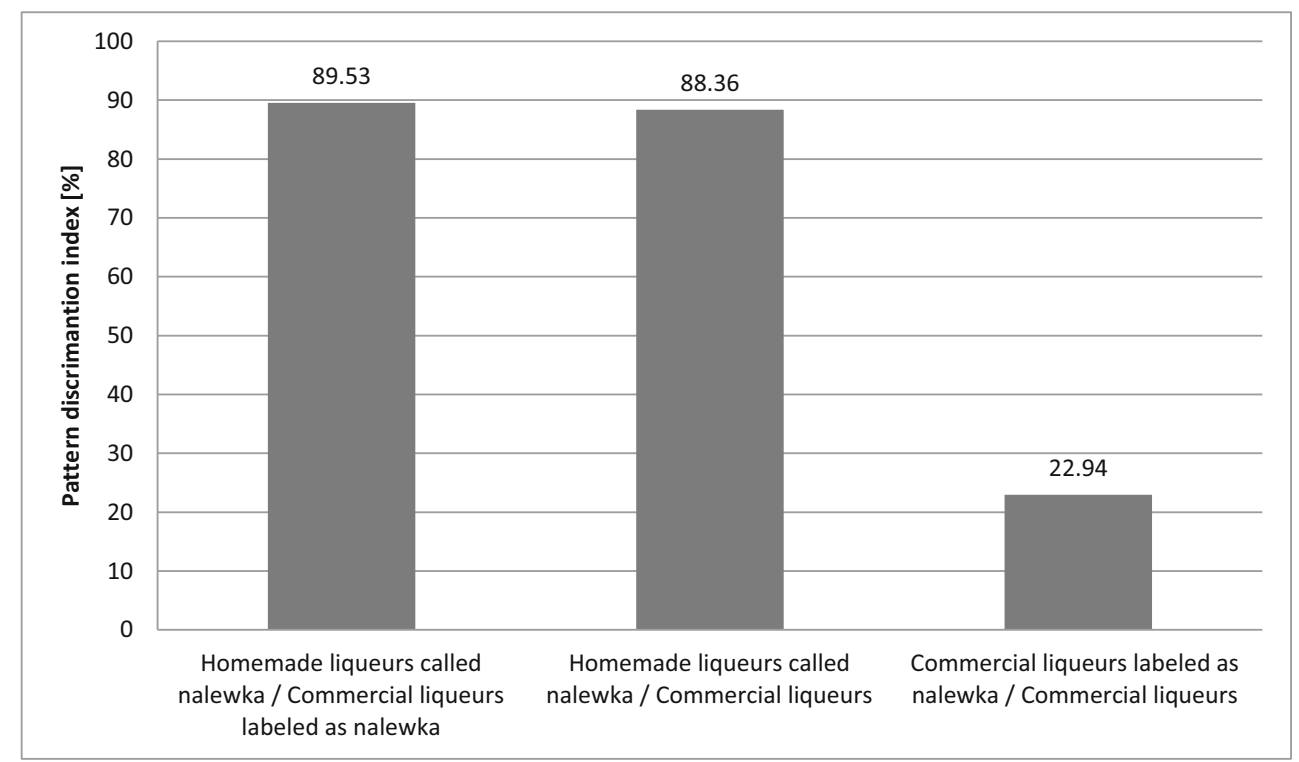


obtained using PCA, DFA, SIMCA, and SQC classification are consistent with all data obtained by means of interpretation of the chromatograms.

\section{Conclusion}

In this work, it has been reported for the first time the utilization of electronic nose based on fast GC for the authenticity assessment of Polish homemade liqueurs called nalewka. Application of this equipment allows for identification of volatile organic compounds present in all three groups of cherry liqueurs and for comparison of aroma profiles of different types of liqueurs. The PCA, SIMCA, and SQC analysis are useful for clear visualization of the differences between homemade and commercial liqueurs. In turn, DFA analysis was the only statistical analysis using which the discrimination of all three groups of liqueurs was possible. Difficulty with distinguishing between these two groups of commercial liqueurs can be explained by the minor differences in aroma profiles. This fact can be explained on the basis of conducted HS-SPME/GC $\times$ GC-TOFMS analysis. The main focus of this work is to broaden knowledge and recognition of Polish traditional product named nalewka and, in future, to propose protection of this traditional product in compliance with the guidelines of the European Union concerning the protection of local and traditional food products.

\section{Acknowledgments}

Funding Magdalena Śliwińska is thankful for "InnoDoktorantScholarships for $\mathrm{PhD}$ students, 6th edition" for financial support. The authors acknowledge the financial support for this study by Grant No. 2012/05/B/ST4/01984 from the National Science Centre of Poland.

\section{Compliance with Ethical Standards}

Conflict of Interest Magdalena Śliwińska declares that she has no conflict of interest. Paulina Wiśniewska declares that she has no conflict of interest. Tomasz Dymerski declares that he has no conflict of interest. Waldemar Wardencki declares that he has no conflict of interest. Jacek Namieśnik declares that he has no conflict of interest.

Ethical Approval This article does not contain any studies with human participants or animals performed by any of the authors.

Informed Consent Not applicable.

Open Access This article is distributed under the terms of the Creative Commons Attribution 4.0 International License (http:// creativecommons.org/licenses/by/4.0/), which permits unrestricted use, distribution, and reproduction in any medium, provided you give appropriate credit to the original author(s) and the source, provide a link to the Creative Commons license, and indicate if changes were made.

\section{References}

Alissandrakis E, Kibaris AC, Tarantilis PA, Harizanis PC, Polissiou M (2005) Flavour compounds of Greek cotton honey. J Sci Food Agric 85:1444-1452

Alissandrakis E, Tarantilis PA, Harizanis PC, Polissiou M (2007) Comparison of the volatile composition in thyme honeys from several origins in Greece. J Agric Food Chem 55:8152-8157

Allegrone G, Belliardo F, Cabella P (2006) Comparison of volatile concentrations in hand-squeezed juices of four different lemon varieties. J Agric Food Chem 54:1844-1848

Andrey D (1987) A simple gas chromatography method for the determination of ethylcarbamate in spirits. Z Lebensm Unter Forsch 185:2123

Beltrán NH, Duarte-Mermoud MA, Soto Vicencio VA, Salah SA, Bustos MA (2008) Chilean wine classification using volatile organic compounds data obtained with a fast GC analyzer. IEEE 57:2421-2436

Bianchi F, Careri M, Mangia A, Musci M (2007) Retention indices in the analysis of food aroma volatile compounds in temperatureprogrammed gas chromatography: database creation and evaluation of precision and robustness. J Sep Sci 39:563-572

Bonvehí JS, Coll FV (2003) Flavour index and aroma profiles of fresh and processed honeys. J Sci Food Agric 83:275-282

Bosch-Fusté J, Riu-Aumatell M, Guadayol JM, Caixach J, LópezTamames E, Buxaderas S (2007) Volatile profiles of sparkling wines obtained by three extraction methods and gas chromatography-mass spectrometry (GC-MS) analysis. Food Chem 105:428-435

Brenntag Food \& Nutrition Europe. Acidulants in food industry - a practical guideline. http://www.brenntag-nordic.com/fi/downloads/ Hapot_TB_Acidulants_FN201310.pdf Accessed 4 November 2015

Buettner A (2004) Investigation of potent odorants and afterodor development in two chardonnay wines using the Buccal Odor Screening System (BOSS). J Agric Food Chem 52:2339-2346

Carasek E, Pawliszyn J (2006) Screening of tropical fruit volatile compounds using solid-phase microextraction (SPME) fibers and internally cooled SPME fiber. J Agric Food Chem 54:8688-8696

Chen HC, Sheu MJ, Wu CM (2006) Characterization of volatiles in guava (Psidium guajava L. cv. Chung-Shan-Yueh-Pa) fruit from Taiwan. J Food Drug Anal 14:398-402

Christoph N, Bauer-Christoph C (2006) Flavour of spirit drinks: raw materials, fermentation, distillation, and ageing. In: Berger RG (ed) Flavours and fragrances chemistry, bioprocessing and sustainability. Springer, Berlin, pp 219-239

Culleré L, Escudero A, Cacho J, Ferreira V (2004) Gas chromatographyolfactometry and chemical quantitative study of the aroma of six premium quality Spanish aged red wines. J Agric Food Chem 52: 1653-1660.

Da Porto C, Pizzale L, Bravin M, Conte LS (2003) Analyses of orange spirit flavour by direct-injection gas chromatography-mass spectrometry and headspace solid-phase microextraction/GC-MC. Flav Fragr J 18:66-72

De Pascual-Teresa S, Treutter D, Rivas-Gonzalo JC, Santos-Buelga C (1998) Analysis of flavanols in beverages by high-performance liquid chromatography with chemical reaction detection. J Agric Food Chem 46:4209-4213

De Rovira SD (2008) Dictionary of flavors. John Wiley \& Sons, Iowa

Demyttenaere JC, Dagher C, Sandra P, Kallithraka S, Verhé R, De Kimpe N (2003) Flavour analysis of Greek white wine by solid-phase microextraction-capillary gas chromatography-mass spectrometry. J Chromatogr A 985:233-246

Dennis MJ, Howarth N, Key PE, Pointer M, Massey RC (1989) Investigation of ethyl carbamate levels in some fermented foods and alcoholic beverages. Food Add Contam 6:383-389 
Echeverría G, Fuentes MT, Graell J, López ML (2003) Relationships between volatile production, fruit quality and sensory evaluation of Fuji apples stored in different atmospheres by means of multivariate analysis. J Sci Food Agr 84:5-20

Escudero A, Campo E, Fariña L, Cacho J, Ferreira V (2007) Analytical characterization of the aroma of five premium red wines. Insights into the role of odor families and the concept of fruitiness of wines. J Agric Food Chem 55:4501-4510

Fan W, Qian MC (2006) Identification of aroma compounds in Chinese 'Yanghe Daqu' liquor by normal phase chromatography fractionation followed by gas chromatography/olfactometry. Flav Fragr J 21:333-342

FAOSTAT (Food and Agriculture Organization of the United Nations Statistic Division). 2012. Production quantity of cherries in Poland in 2012. Available from: http://faostat.fao.org/site/567/ DesktopDefault.aspx?PageID=567\#ancor. Accessed 25 October 2015

Fiedoruk A (2006) Polskie nalewki i wódki (English translation: Polish nalewkas and vodkas). Dragon, Bielsko Biała

Ghasemi-Varnamkhasti M, Rodríguez-Méndez ML, Saeid Mohtasebi S, Apetrei C, Lozano J, Ahmadi H, Hadi Razavi S, De Saja JS (2012a) Monitoring the aging of beers using a bioelectronic tongue. Food Control 25:216-224

Ghasemi-Varnamkhasti M, Saeid Mohtasebi S, Rodríguez-Méndez ML, Gomes AA, Ugulino Araújo MC, Galvăo RKH (2012b) Screening analysis of beer ageing using near infrared spectroscopy and the successive projections algorithm for variable selection. Talanta 89: 286-291

Gürbüz O, Rouseff JM, Rouseff RL (2006) Comparison of aroma volatiles in commercial Merlot and Cabernet Sauvignon wines using gas chromatography - olfactometry and gas chromatography - mass spectrometry. J Agric Food Chem 54:3990-3996

Hallgarten PA (1983) Spirits and liqueurs. Faber and Faber, London

Hernández Gómez LF, Úbeda J, Arévalo-Villena M, Briones A (2009) Novel alcoholic beverages: production of spirits and liqueurs using maceration of melon fruits in melon distillates. J Sci Food Agr 89: 1018-1022

Ieri F, Pinelli P, Romani A (2012) Simultaneous determination of anthocyanins, coumarins and phenolic acids in fruits, kernels and liqueur of Prunus mahaleb L. Food Chem 135:2157-2162

Jordán MJ, Margaría CA, Shaw PE, Goodner KL (2002) Aroma active components in aqueous kiwi fruit essence and kiwi fruit puree by GC-MS and multidimensional GC/GC-O. J Agric Food Chem 50: $5386-5390$

Joulain D, Casazza A, Laurent R, Portier D, Guillamon N, Pandya R, Le M, Viljoen A (2004) Volatile flavor constituents of fruits from Southern Africa: mobola plum (Parinari curatellifolia). J Agric Food Chem 52:2322-2325

Kundu K, Mitra S, Mazumdar D, Pal SK (2006) Perception and machine intelligence. Springer, New York

Lachenmeier DW (2005) Rapid screening for ethyl carbamate in stonefruit spirits using FTIR spectroscopy and chemometrics. Anal Bioanal Chem 82:1407-1412

Lachenmeier DW, Frank W, Kuballa T (2005) Application of tandem mass spectrometry combined with gas chromatography to the routine analysis of ethyl carbamate in stone-fruit spirits. Rapid Commun Mass Spectrom 19:108-112

Lachenmeier DW, Nerlich U, Kuballa T (2006) Automated determination of ethyl carbamate in stone-fruit spirits using headspace solid-phase microextraction and gas chromatography-tandem mass spectrometry. J Chromatogr A 1108:116-120

Lee SJ, Noble AC (2003) Characterization of odor-active compounds in Californian chardonnay wines using GC-olfactometry and GC-mass spectrometry. J Agric Food Chem 51:8036-8044
Lermusieau G, Bulens M, Collin S (2001) Use of GC-olfactometry to identify the hop aromatic compounds in beer. J Agric Food Chem 49:3867-3874

Mahattanatawee K, Goodner KL, Baldwin EA (2005) Volatile constituents and character impact compounds of selected Florida's tropical fruit. Proc Fla State Hort Soc 118:414-418

Maia JGS, Andrade EHA, Zoghbi MB (2004) Aroma volatiles from two fruit varieties of jackfruit (Artocarpus heterophyllus Lam.). Food Chem 85:195-197

Mattheis JP, Fan X, Argenta LC (2005) Interactive responses of gala apple fruit volatile production to controlled atmosphere storage and chemical inhibition of ethylene action. J Agric Food Chem 53: $4510-4516$

Murakami A, Goldstein H, Navarro A, Seabrooks JR, Ryder DS (2003) Investigation of beer flavor by gas chromatography-olfactometry. $\mathrm{J}$ Am Soc Brew Chem 1:23-32

Namara KM, Leardi R, Sabuneti A (2005) Fast GC analysis of major volatile compounds in distilled alcoholic beverages: optimisation of injection and chromatographic conditions. Anal Chim Acta 542:260-267.

Narain N, De Sousa Galvão M, Madruga MS (2007) Volatile compounds captured through purge and trap technique in caja-umbu (Spondias sp.) fruits during maturation. Food Chem 102:726-731

Nikićević N, Veličković M, Jadranin M, Vučković I, Novaković M, Vujisić L, Stanković M, Urošević I, Tešević V (2011) The effects of the cherry variety on the chemical and sensorial characteristics of cherry brandy. J Serb Chem Soc 76:1219-1228

Olsson J, Börjesson T, Lundstedt T, Schnürer J (2000) Volatiles for mycological quality grading of barley grains: determinations using gas chromatography-mass spectrometry and electronic nose. Intl J Food Microbiol 10:167-178

Peng Q, Tian R, Chen F, Li B, Gao H (2015) Discrimination of producing area of Chinese Tongshan kaoliang spirit using electronic nose sensing characteristics combined with the chemometrics methods. Food Chem 178:301-305

Perestrelo R, Fernandes A, Albuquerque FF, Marques JC, Câmar JS (2006) Analytical characterization of the aroma of Tinta Negra Mole red wine: identification of the main odorants compounds. Anal Chim Acta 563:154-164

Pino J, Marbot R, Vazquez C (2005) Volatile constituents of genipap (Genipa americana L.) fruit from Cuba. Flav Fragr J 20:583-586

Pino JA, Almora K, Marbot R (2003) Volatile components of papaya (Carica papaya L., maradol variety) fruit. Flav Fragr J 18:492-496

Plutowska B, Wardencki W (2008) Determination of volatile fatty acid ethyl esters in raw spirits using solid phase microextraction and gas chromatography. Anal Chim Acta 613:64-73

Polak J, Bartoszek M (2015) The study of antioxidant capacity of varieties of nalewka, a traditional Polish fruit liqueur, using EPR, NMR and UV-vis spectroscopy. J Food Comp Anal 40:114-119

Quijano CE, Linares D, Pino JA (2007) Changes in volatile compounds of fermented cereza agria [Phyllanthus acidus (L.) Skeels] fruit. Flav Fragr J 22:392-394

Ragazzo-Sanchez JA, Chalier P, Chevalier D, Calderon-Santoyo M, Ghommidh C (2008) Identification of different alcoholic beverages by electronic nose coupled to GC. Sens Actuators B 134:43-48

Ragazzo-Sanchez JA, Chalier P, Chevalier-Lucia D, Calderon-Santoyo M, Ghommidh C (2009) Off-flavours detection in alcoholic beverages by electronic nose coupled to GC. Sens Actuators B 140:29-34

Regulation [EC] No (2008) 110/2008 of the European Parliament and of the Council on the definition, description, presentation, labelling and the protection of geographical indications of spirit drinks and repealing

Riu-Aumatell M, Bosch-Fusté J, López-Tamames E, Buxaderas S (2006) Development of volatile compounds of cava (Spanish sparkling 
wine) during long ageing time in contact with lees. Food Chem 95: 237-242

Rødtjer A, Skibsted LH, Andersen ML (2006) Antioxidative and prooxidative effects of extracts made from cherry liqueur pomace. Food Chem 99:6-14

Rouseff R, Jella P, Bazemore R, Yang J (2009) Aroma active internal standards for gas chromatography-olfactometry of grapefruit juices. ACS Symp Ser 782:73-87

Sampaio TS, Nogueira PCL (2006) Volatile components of mangaba fruit (Hancornia speciosa Gomes) at three stages of maturity. Food Chem 95:606-610

Setkova L, Risticevic S, Pawliszyn J (2007) Rapid headspace solid-phase microextraction-gas chromatographic-time-of-flight mass spectrometric method for qualitative profiling of ice wine volatile fraction II: classification of Canadian and Czech ice wines using statistical evaluation of the data. J Chromatogr A 1147:224-240

Seung-Joo L, Jang-Eun L, Hyeon-Wee K, Sung-Soo K, Kyung-Hee K (2006) Development of Korean red wines using Vitis labrusca varieties: instrumental and sensory characterization. Food Chem 94: 385-393

Śliwińska M, Wiśniewska P, Dymerski T, Namieśnik J, Wardencki W (2014) Food analysis using artificial senses. J Agric Food Chem 19:1423-1448

Śliwińska M, Wiśniewska P, Dymerski T, Wardencki W, Namieśnik J (2015) The flavour of fruit spirits and fruit liqueurs: a review. Flav Fragr J 30:197-207

Sun SY, Jiang WG, Zhao Y (2010) Characterization of the aroma-active compounds in five sweet cherry cultivars grown in Yantai (China). Flav Fragr J 25:206-213

Tešević V, Nikićević N, Milosavljević S, Bajić D, Vajs V, Vučković I, Vujisić L, Dordevic I, Stanković M, Velićković M (2009) Characterization of volatile compounds of "Drenja", an alcoholic beverage obtained from the fruits of cornelian cherry. J Serb Chem Soc 74:117-128

The Good Scents Company Information System, http://www. thegoodscentscompany.com/data/rw1004931.html. Accessed 4 November 2015

Tsakiris A, Sipsas V, Bekatorou A, Mallouchos A, Koutinas AA (2004) Red wine making by immobilized cells and influence on volatile composition. J Agric Food Chem 10:1357-1363

Wilson DM, Dunman K, Roppel T, Kalim R (2000) Rank extraction in tin-oxide sensor arrays. Sens Actuators B 62:199-210

Wiśniewska P, Śliwińska M, Dymerski T, Wardencki W, Namieśnik J (2015a) Application of gas chromatography in analysis of spirit beverages. Crit Rev Anal Chem 45:201-225

Wiśniewska P, Śliwińska M, Dymerski T, Wardencki W, Namieśnik J (2015b) Differentiation between spirits according to their botanical origin. Food Anal Met. doi:10.1007/s12161-015-0280-x

Xiao Z, Yu D, Niua Y, Chen F, Song S, Zhu J, Zhu G (2014) Characterization of aroma compounds of Chinese famous liquors bygas chromatography-mass spectrometry and flash GC electronic-nose. J Chromatogr B 945-946:92-100

Xu Y, Fan W, Qian MC (2007) Characterization of aroma compounds in apple cider using solvent-assisted flavor evaporation and headspace solid-phase microextraction. J Agric Food Chem 55:3051-3057

Yang Y, Zhao Y, Zhang S, Ni Y, Zhan J (2012) Qualitative analysis of age and brand of unblended brandy by electronic nose. In: Li VD, Chen $\mathrm{Y}$ (eds) Computer and computing technologies in agriculture V, IFIP advances in information and communication technology. Springer, Berlin, pp 619-628

Zimmerli B, Schlatter J (1991) Ethylcarbamate: analytical methodology, occurrence, formation, biological activity and risk assessment. Mutat Res Gen Tox 259:325-350 